\title{
Recognition of prior learning: the accelerated rate of change in Australian universities
}

\section{Tim Pitman}

To cite this article: Tim Pitman (2009) Recognition of prior learning: the accelerated rate of change in Australian universities, Higher Education Research \& Development, 28:2, 227-240, DOI: 10.1080/07294360902725082

To link to this article: https://doi.org/10.1080/07294360902725082

曲 Published online: 11 Mar 2009.

Submit your article to this journal $\pi$

山ll Article views: 272

Q View related articles $\asymp$

Citing articles: 13 View citing articles 


\section{Recognition of prior learning: the accelerated rate of change in Australian universities}

Tim Pitman*

University of Western Australia, 35 Stirling Highway, Crawley WA 6009, Perth, Australia

(Received 27 June 2007; final version received 25 July 2008)

The recognition of prior learning (RPL) is a cornerstone of the lifelong learning policies of most developed nations. Yet the scholarly view in Australia has been that, unlike other post-compulsory education sectors, universities have erected barriers to limit the development of RPL. This paper re-examines the current policy environment and finds evidence that universities are now more active in developing and promoting RPL, as evidenced by the rich detail of information contained in recent policies, as well as the accessibility of this information on the web. Recognition of prior learning policies are examined in detail to shed light further on the state of play of RPL in the Australian higher education sector.

Keywords: credit transfer; higher education policy; informal learning; lifelong learning; recognition of prior learning

\section{Introduction}

Universities have always been jealous guardians of knowledge and its production (Davison, 1996; Michelson, 1996). Yet since the latter part of the twentieth century there has arisen mounting pressure for higher education institutions to recognise learning acquired outside of a formal context, for reasons of social equity, improved access to education for traditionally under-represented groups and the development of a 'lifelong learning' culture within the broader community (Cameron, 2004; Gallacher \& Feutrie, 2003; Taylor \& Clemans, 2000). This is known as the recognition of prior learning (RPL). Furthermore, RPL is considered a powerful incentive for individuals to access formal and further education, consequently improving their job prospects (International Labour Office, 2004, p. 12).

At its inception in Australia, there appeared to be ample support for RPL from within the higher education sector. In 1989 the National Board of Employment, Education and Training (NBEET) and the Higher Education Council called on universities to 'take account of work experience wherever possible', an appeal that was met with in-principle agreement from the outset (NBEET, 1990, pp. 2-3). Recognition of prior learning was formally introduced into Australian curricula in 1993 as part of the Australian Qualifications Framework (AQF) (Cameron, 2004). In the same year, the Australian Vice Chancellors' Committee (AVCC, 1993) gave it in-principle support. The first identifiable university policy written specifically

*Email: tim.pitman@uwa.edu.au 
for RPL appeared in June of the following year at the Central Queensland University (CQU). In it the university encouraged its faculties to develop their own, more specific, policies as they grew in experience 'through a better understanding of the academic bases of certain types of prior learning, or by evaluation of a number of requests for recognition of the same type of prior learning' (CQU policy on 'Recognition of Prior Learning', 1994). By 2000, at least eleven Australian universities - representing every associated university group (e.g. Group of Eight, Australian Technology Network etc.) had formalised their position on RPL in writing. Many more institutions accepted RPL, even in the absence of a written policy.

Yet recent literature reveals evidence that despite this early in-principle agreement, in practice universities far prefer recognition of prior credentialed learning, also known as credit transfer (Childs, Ingham, \& Wagner, 2002; Doddrell, 2002; Fox, 2005; Wheelahan et al., 2003). These scholars argue that this has created significant barriers for prospective students attempting to gain recognition for informal learning such as work or life experience. Furthermore, according to Wheelahan et al. (2003), using data obtained from the Australian Bureau of Statistics in 2002, 26\% of students studying a bachelor's degree at university received credit based on credit transfer, compared to only $4 \%$ of students using RPL (p. 67). These proportions were virtually identical to those of a decade ago (NBEET, 1994, p. 5). Fox (2005) has suggested that efforts made by the AVCC to address the relatively low impact of RPL in higher education, appear to have only served to further entrench extant credit transfer models. The Federal government - the largest sole educational shareholder in financial terms - has in the past provided rhetorical support for the recognition of all forms of prior learning in post-compulsory education (Department of Education Science and Training, 2002; Nelson, 2005; West, 1998). However, assistance of a more substantive nature for the development of support mechanisms for RPL has not yet been forthcoming. In the absence of this encouragement it is the conclusion of most recent scholarship up to and including 2003 that universities remain unwilling to facilitate a process for which they feel no ownership and are not being provided leadership (see, for example, Doddrell, 2002). The evidence uncovered by these researchers gives credence to these assertions.

It is now more than five years since the most recent of these studies was published and it is timely to re-examine the prevalence (or otherwise) of RPL practice in Australian universities. Quite apart from the time that has passed, several important events have occurred that makes further examination useful. Most significantly, the groundbreaking research conducted by Wheelehan et al. (2003) provided the foundation for the current AQF National Principles and Operational Guidelines for Recognition of Prior Learning, which were endorsed in June 2004 and adopted in the same year by the AVCC as a de facto policy position. To date, there has been no research on the effect that the AVCC endorsement of the principles has had, within a rapidly changing tertiary environment. Furthermore, a fresh perspective may indicate the extent to which universities have altered their position on RPL. An analysis of policy content allows the researcher to move beyond whether or not RPL is accepted at the institution, but in what ways. How do universities define RPL? How do they express the value they place on it or the institutional aims they see it as supporting? What conditions or limitations are placed on this acceptance? 


\section{The need for a framework to guide RPL in the Australian higher education sector}

As previously mentioned, from as early as 1989 NBEET called upon Australian universities to recognise non-formal learning, such as work or life experience, for the purposes of admission into, or credit towards, tertiary degrees. And, as also observed, the sector was happy to agree with this in principle. However, as to how, exactly, this could be done, the sector remained unsure (NBEET, 1990, p. 2). Other than policymaking at the individual (i.e. university) level, the first meaningful action came in 1993, when the AVCC adopted a policy covering credit transfer and RPL. There were seven guidelines for credit transfer and a further seven for RPL. However, a closer examination of the RPL principles reveals that at this time the AVCC definition of RPL was non-specific, as it encompassed all prior learning acquired outside of the state-controlled and administered Technical and Further Education institutions (TAFE). Recognition of prior learning, insofar as it referred to non-formal learning, was not yet dealt with in its own right. The AVCC itself recognised that further work on developing RPL policy was required (Wheelahan et al., 2003, p. 77). Yet, when the AVCC (2003) released further information for the development of linkages between the VET and higher education sectors, they stated:

Because the RPL process does not involve a linkage between one qualification and another it is seen as outside the scope of this project. (p. 46)

No complementary report for RPL was forthcoming. Time and again, RPL appeared to be subsumed into a general discussion about prior learning (both credentialed and uncredentialed) and from there lost, as the discussion focused singularly on credit transfer.

It is not just the AVCC that has been complicit - other educational stakeholders have also been guilty in the past of promoting credit transfer over and above RPL. In 1998 the Federal Government released its white paper on higher education entitled Learning for life (West, 1998). The report totalled 229 pages and made 38 individual recommendations. Credit transfer was frequently in the report as an issue. However not once in the report - let alone the recommendations - was RPL referred to, despite the supposed focus on lifelong learning of the report. In 2002 the new Minister for Education, Dr Brendan Nelson, published Varieties of learning: The interface between higher education and vocational education and training (VET), which sought to promote a national system of credit transfer between VET and higher education (Department of Education, Science and Training, 2002, p. ix). No such similar action was taken in respect of RPL. In 2005 the Ministerial Council on Education, Employment, Training and Youth Affairs released its Principles for good practice information provision on credit transfer and articulation from vocational training and education to higher education. The aim of these principles was to 'improve credit transfer and articulation from VET to higher education' via the 'access of information that enables them to make well-informed choices about where and what they should study'. Again, no such similar action was taken to ensure that information concerning RPL would also be provided in a similar fashion. A recent content analysis of parliamentary records of all Australian state and territory parliaments from 2000-2005 reveals a pattern of repeated political pressure by MPs to encourage universities to improve credit transfer and articulation arrangements with VET. Yet, over the same period, the issue of RPL in higher education has passed by virtually un-remarked 
(Pitman, 2006). The evidence up until very recently, therefore, indicated a chronic under-representation of RPL in the higher education sector, by stakeholders from both within and without.

However, in May 2002, the AQF Advisory Board commissioned a project to research existing policies and practices relating to RPL in the senior secondary school; adult and community education; vocational education and training; and higher education sectors in Australia with a view towards developing cross-sectoral, national RPL principles and operational guidelines. A direct consequence of the project was the creation of the AQF National principles and operational guidelines for recognition of prior learning (hereafter referred to as the AQF Guidelines), which were endorsed in June 2004. These principles exhort all sectors of post-compulsory education (including universities) to develop RPL policies and procedures that ensure opportunities for all Australian to 'have their non-formal and informal learning recognised and counted towards a qualification', as well as 'consistency in the principles used in implementing RPL within sectors and between sectors' (http:// www.aqf.edu.au/rplnatprin.htm). Crucially, the AQF Guidelines have been fully endorsed by the AVCC. This is the latest - and arguably the most significant attempt by the AVCC (albeit in a de facto manner) to identify and explicate the value it places on RPL. To date there has been no research into the impact, if any, that these principles have had on the sector. Previous research into RPL policy (Childs et al., 2002; Doddrell, 2002; Wheelahan et al., 2003) has been conducted prior to the implementation of the AQF Guidelines. Indeed, as previously stated, the Wheelahan et al. research was instrumental in the development of these Guidelines. It is therefore unknown whether extant university policies on recognition of prior learning (1) seek to separate RPL from credit transfer as recommended and (2) incorporate the AQF Guidelines as recommended by the AVCC. This paper directly addresses this gap in the research and provides a contemporary analysis of how RPL policy is being developed in Australian universities.

\section{Methods}

The research underlying this study comprised two stages. The first stage involved a content analysis of university policies concerned with RPL. Content analysis is a research method developed specifically for investigating any problem in which the content of communication serves as the basis of inference (Holsti, 1969, p. 2). Content analysis is a particularly effective tool to audit communication content against objectives (Berelson, 1952). In this instance the communication content was the policy documents and the objective was the match (or mismatch) to the questions posed by this study (see below). Content analysis alleviated the problem of data accessibility as university policies were freely available in the public domain via the web. Thirty-eight universities were included in the analysis. The data for the content analysis was drawn from publicly available policy documents including universities' policies, statutes, rules, protocols and handbooks. These documents were available online via the universities' home page. The web presents unparalleled opportunities for quick, cost-effective and accurate data collection (Duffy, 2002) and allows researchers access to potentially difficult to reach data (Wright, 2005). There are concerns that online data collection may be ad hoc and subject to missing 'events' framed in unusual ways (Earl, Martin, McCarthy, \& Soule, 2004, p. 75), however the risk for this study was minimal, since the data collection points (i.e. university web 
sites) were easily located and framed. Furthermore, the existence or non-existence of each online policy was double-checked through direct contact with each university, to confirm the correct policy had been identified or, indeed, did not exist. Once collected, the data was coded into 'context units' (that is, phrases, sentence or sections) that related wholly or partly to RPL such as: limitations, definitions, rules, principles or guidelines.

This approach revealed the extent to which RPL was being considered in its own right, rather than being subsumed into a more general discussion relating to admission and credit based primarily on credentialed learning. Additionally it revealed conceptual notions of importance, value and equity. This allowed the topic of RPL in higher education to be located and contextualised within the broader notions of teaching and learning. It must be acknowledged, however, that content analysis is essentially a process of reduction. Any reductionist approach such as this carries with it two inherent dangers. Firstly it is possible - notwithstanding the systematic approach taken to data collection as described above - that all extant literature on the topic was not identified. For example, there may also exist non-RPL specific documents in some institutions that nonetheless inform RPL policy. Secondly, it is necessary for the researcher to make value judgments as to how findings are to be interpreted and prioritised. It is therefore possible that the resulting analysis carries within it certain deficiencies due to the value judgements that were made. In this respect it is useful for the researcher to identify himself as a male research student with over ten year's professional experience in Australian universities, including the area of RPL. Finally, it is acknowledged that policy documents do not necessarily reflect how policy is ultimately enacted. However, as Stephen Ball (1994) has observed, whilst policy documents are invariably subject to compromises at various stages of the policy process, "nonetheless policies are textual interventions into practice; and although many [readers] are proactive ... their readings and reactions are not constructed in circumstances of their own making' (p. 48).

The second stage of the study addressed the issue of accessibility of the RPL information from the point of view of both current and prospective students, as well as university staff involved in the RPL process. Using the information discovered via the content analysis, an online search was conducted to evaluate the accessibility of that information. The information being searched for was either the RPL policy document or equivalent information, such as a web page for prospective students about RPL at the university. In the case of the latter, the information had to cover the essential elements of the actual RPL policy such as its key principles and what action had to be taken by the applicant to initiate an assessment of prior learning (forms, deadlines, contact information). In other words, either the actual, ratified policy or a 'virtual' policy had to be located.

Accessibility was determined by three criteria. Firstly, the information had to be located via a web search initiated from the university's home page using its default search engine. Secondly, the search had to use either the term 'RPL' or 'recognition of prior learning'. Finally, the online search had to identify the information in the first page of 'hits', i.e. not require the searcher to trawl through additional pages of information. This data was then collated to provide a holistic picture of the extent to which information concerning RPL policy is being made available within the higher education sector. In respect especially of the final two criteria it is acknowledged that 'accessibility' is largely a value judgement of the researcher; however it is believed that this definition is one that would meet with broad consensus. 


\section{Data collection}

For this study, the definition of a university was restricted to those organisations that were members of the AVCC, since it was these institutions that had given in-principle agreement to the AQF Guidelines. This gave a total of 38 universities. The data were collected over a six-month period in 2006-2007 and a final update of the data was conducted during the writing of this paper.

It is pertinent to observe that during the initial six-month period of collection several policies were added or amended, with further additions and amendments noted as this paper was revised. It is therefore highly probable that by the time this paper is published even more changes will have occurred. This is in itself indicative of the rate of change currently occurring if not in higher education policy in general, then certainly in the area of RPL.

\section{Research questions}

Where the university did provide a policy covering RPL, the content analysis stage was guided by the following questions:

(1) Was the document specifically for RPL (as opposed to credit for prior learning in general) or did it at least provide for elements (e.g. rules, processes, guidelines) that were specific to RPL; and

(2) Was there any evidence that the institution in question had acted to incorporate the AQF Guidelines, as endorsed by the AVCC?

The second part of the study was guided, as is described above, by the extent of accessibility of policy information on the web.

\section{Findings}

\section{Content analysis}

Acceptance of RPL

Most universities now accept RPL. Specifically, 29 of the 38 universities (76.3\%) confirmed that they accepted RPL for the purposes of admission and/or credit, including one university who only accepted RPL for postgraduate courses. Of the 29 universities, 26 had an associated online policy, with the remaining three accepting RPL without any formal policy in support. The figure of 29 is greater than any previous study has identified: Childs et al. (2002) identified 13, whilst Wheelahan et al. (2003) identified 26. It is not possible to draw any meaningful comparisons with Doddrell's 2002 study because only half the universities responded to the request for documentation and therefore determining the number who accepted RPL was hard to substantiate (p. 91). This new study also found that 11 of the 26 RPL policies had an approval date later than 2002; in other words they are policies that were not in existence (at least in their current form) at the time that Doddrell or Childs et al. did their research. There is every indication, therefore, that more universities have been active in developing RPL policy in recent years.

\section{Existence of RPL-specific policies}

Of the 26 universities' RPL documents identified, six could be described as 'standalone' RPL documents. By stand-alone it is meant a policy with the sole purpose of 
explicating the institution's position on the recognition of prior informal learning. In these six cases, the universities also had complementary policies on credit transfer. The remaining institutions' policies were documents that described the university's policy on prior learning in general, i.e. both RPL and credit transfer. Clearly, the preference was to include RPL with a general policy on all forms of prior learning. These policies were labelled in a multitude of ways including:

- Skills Recognition

- Advanced Standing, Credit and Exemption

- Recognition of Prior Learning (referring to both credentialed and uncredentialed learning)

- Credit and Advanced Standing

- Rules on Credits and Exemptions

- Credit for Previous Studies and Recognised Prior Learning

This supports earlier contentions that RPL in the higher education sector suffers from lack of clarity and consistency in definitions and terms (Childs et al., 2002; Doddrell, 2002). Furthermore, account should be taken of the observation that by failing to consider RPL independently of credit transfer, universities were not adequately developing associated processes that might, in turn, act as a mechanism for social inclusion for disadvantaged groups in tertiary education (Wheelahan et al., 2003). However, it also true that a further seven policies dealt with the issue of RPL in a significant manner. By 'significant' it is meant either a policy with a section dedicated to RPL, including rules, procedures or guidelines specific to experiential learning and in some way distinct from those for credit transfer' or a policy clearly delineating RPL from credit transfer via a combination of definitions, procedures, rules or guidelines throughout the policy. Examples of this type of 'significant' distinction included the following statements:

All course proposals and review documents will include broad skills recognition issues, in addition to credit transfer and articulation, [author's emphasis] where it is appropriate to do so. (Charles Darwin University, 1999)

Recognised Prior Learning (RPL) - refers to previous informal studies that involved learning that is less structured in nature and that can be demonstrated to be of equivalence to appropriate University of Queensland studies. (University of Queensland, 2005)

\section{Recognised prior learning definitions}

Of the 26 policies, $18(64 \%)$ provided a precise definition of RPL, as opposed to a generic definition for all forms of prior learning. These definitions acted to identify the 'learning' implicit in RPL as a non-traditional - but entirely valid construct:

recognition of skills and knowledge gained through work experience, life experience and/or formal training (University of South Australia, 1993)

(a) learning gained from work experience; (b) learning gained from non-credentialed courses; (c) learning from life (University of Canberra, n.d.)

One chose to invoke the AVCC guidelines as a form of authority: 
The Australian Vice-Chancellors' Committee (AVCC) defines 'Recognition of Prior Learning' (RPL) as admission to, or academic credit for, a course of study based on previous, non-academic life experience. (University of Newcastle, 2000)

Many definitions were notably disparate and (with the exception of those who used the AVCC definition) no two were exactly alike. In one sense, however, they are similar: they all acted to separate the notion of RPL from other forms of more traditional learning, such as the concept of credit transfer.

Many universities described the environment in which the policy had been developed and/or operates. These statements ranged from the bureaucratic:

The following resolutions of the Academic Board must be read in conjunction with the University of Sydney (Amendment Act) Rule 1999 Part 9: Admission to Courses, Division 8 and the University of Sydney (Coursework) Rule 2000. (University of Sydney, 1998)

To the philosophical:

The movement towards competency-based approaches to post-compulsory education and training in Australia which had its beginnings in the late-80s has had a number of outcomes, including ... the establishment of a climate in which articulation between courses at different levels and recognition of prior learning are very strongly supported. [This] is a natural flow-on from a movement which places primary emphasis on what a person can do as a result of training, rather than on the nature of the processes involved in that training. (University of Western Australia, 1995)

The former statement suggests a document written for a specific, internal audience; namely those involved in the process of administering, assessing and applying RPL and, to a lesser extent, those concerned with providing information to applicants. The latter appears to be directed to the organisation's broader community and is less concerned with process and more focussed on the wider, ideological considerations of the nature of RPL within the institution.

Eleven institutions made direct reference to the AVCC 1993 guidelines on credit transfer and RPL. A further seven explicitly referred to the associated guidelines on RPL contained in this document. Again, several used the AVCC guidelines to situate their own policy within a broader social context and empower their own document:

The University, consistent with the Australian Vice-Chancellors' Committee guidelines, believes that access and equity for students are improved by RPL. (University of Newcastle, 2000)

Conversely, one used the same construct to distance itself from the AVCC position:

The AVCC's response to the increased emphasis on appropriate recognition of prior learning has been to accept responsibility for the improvement of national consistency in the treatment of applications ... [However] the University has to date been cautious in its approach ... to the pressure [author's emphasis] for increased RPL ... (University of Western Australia, 1995)

This statement clearly identifies the University as highly aware of the broader policy context, yet unwilling to yield to external pressure to conform with the RPL guidelines supported by the majority of its peers. 
Valuing $R P L$

Several universities explicated the value of RPL within their policy documents. This was demonstrated by statements such as:

[the RPL process will] encourage a sense of lifelong and continuous learning, whereby a student should be able to transfer the knowledge and skills gained in one context or environment into others throughout his or her life. (Charles Darwin University, 1999)

[T]his policy for Recognition of Prior Learning (RPL) provides for ... opportunities for non-formal and informal learning to be recognised for purposes of entry to a course or obtaining credit towards an undergraduate or postgraduate qualification [and] recognition of diverse and inclusive pathways to lifelong learning. (Australian Catholic University, 2003)

By recognising students' past experiences and achievements, the University ensures that students do not repeat the skills and knowledge they have already achieved. In this way students are able to shorten the length of their course, saving time and money. They study at the appropriate level, are encouraged to continue their learning and achieve their educational goals with maximum efficiency. (Victoria University, n.d.)

These declarations appeared to represent a conscious effort by the universities to place both a social and economic value on RPL. The idea of 'value' frequently occurred:

[The University] supports an approach which values all learning, however achieved, through an open and transparent approach to assessment. It acknowledges that learning may be achieved through either non-formal or informal pathways, and that provision should exist for recognition of these. (Australian Catholic University, 2003)

These statements contain, in fact, three aspects of value. The first is that RPL is as valuable as other forms of learning (i.e. 'values all learning'). The second is that RPL is, in itself, a 'worthy' form of learning. Finally, RPL has a resources value, as it reduces the time and cost involved in obtaining a degree. Thus, RPL can be, simultaneously, inherently, comparably and quantifiably valuable.

\section{RPL and quality assurance}

Almost three-quarters ( $72 \%)$ of the policies contained guidelines on quality assurance procedures, to ensure the integrity of the prior learning process. Many of these were specifically written for RPL and embraced issues such as the requirement to where necessary seek external advice on RPL assessment, conduct regular reviews of RPL processes and ensure that relevant staff were appropriately trained in RPL assessment. Some of these statements raised the importance of RPL beyond its specificity and entrenched it in core teaching and learning functions such as 'all course proposals and review documents will include broad skills recognition issues' (Charles Darwin University). Quality assurance was inextricably linked to the protection of the academic integrity of the university's degrees. A key principle in this respect was the use of limitations or restrictions governing the maximum amount of RPL that may be awarded. By limiting maximum credit to, for example, one year of study, institutions ensured that the majority of the degree was covered by curriculum developed within the institution, ensuring a high degree of 'brand' assurance in the wider community. Furthermore, most universities accepting RPL included a requirement that credit 
given must be linked to specific learning outcomes, usually expressed as units of study. The preference is to give 'specific' credit, as opposed to general, or 'block' credit. In all, there were 19 references to the need for RPL to match specific learning outcomes, as expressed as units of study: 'Where ever possible, specified credit should be granted' (Griffith University, 2006); 'The [RPL] application should outline the link between those learning experiences and the learning outcomes of the unit(s)/course in which the student is seeking credit' (Monash University, 2002).

Limitations thus also acted as a quality assurance process by maintaining the primacy of the universities' own curriculum. There are, however, at least two negative conclusions (from the point of view of RPL proponents) that can be drawn from these limitations. The first is that these requirements are disconnected from learning: regardless of the prior competencies of the applicant, there is a credit maximum beyond which they cannot exceed. The second is that a preference for specific credit tends to bias applicants with documented (i.e. credentialed) learning. Informal learning is often more generic or holistic and benefits from a corresponding assessment mechanism. The requirement to match learning to specific unit outcomes is a potential barrier to the recognition of informal learning. It is also evidence of the continuing bias towards credit transfer arrangements at the functional (i.e. process) level of the policies.

\section{Influence of the AVCC-endorsed AQF guidelines}

Only one university - Edith Cowan University (n.d.) - was found to have mentioned the AQF Guidelines by name. Upon closer examination it was discovered that, at the time of this survey, only six institutions had policies with identifiable approval dates later than June 2004 (i.e. the date when the AVCC endorsed the Guidelines). It is much more difficult to assess the extent to which the policies had been indirectly influenced by the actions of the AQF and AVCC in this respect. For example, a university would probably not consider it necessary to update their policy postendorsement, if they believed that it already conformed to the new Guidelines.

\section{Accessibility}

Childs et al. (2002) identified 13 universities as 'mentioning RPL by name' (p. 46). By contrast, this study has found that each of the 29 universities that accepted RPL mentioned it by name within their website. Furthermore, 22 of the 29 universities (76\%) accepting RPL made that policy accessible online. In other words, a direct link to the policy or a 'virtual' policy could be found in the first page of search results. Of interest is the fact that in each case the information could be found just by typing 'RPL'. This is the first indication that the higher education sector is moving to standardise terminology in describing RPL, although as this study has shown this has not yet been reflected in the titles of the associated policies. Nevertheless, there are positive signs that prospective students are beginning to find a degree of commonality of language and terms, when comparing RPL across university websites.

\section{Conclusion}

This study found significant evidence that the profile of RPL in Australian universities is increasing insofar as it can be measured in formal policy positions and documents, 
including their online accessibility. Most universities continue to provide a 'blanket' policy on the recognition of prior learning and do not provide a separate document specific to RPL. However, more than three-quarters of Australian universities now indicate that they accept RPL and, of those, 90\% provide a publicly available document outlining their institutional policies, processes and guidelines on RPL. More than half of the policies deal with RPL either exclusively or in a significant manner, including precise definitions, institutional aims and guidelines on how informal learning should be measured.

Many institutions' policy documents remain weighted towards credit transfer. If the analysis underlying this paper is considered in isolation to earlier studies, then it could be said that universities still prefer RPL to credit transfer. However, when this study is placed in context with the others, it appears that in a relatively short period of time the higher education sector has moved significantly in its conceptual understanding, and acceptance, of RPL.

There is probably no sole reason for this evolution, though several factors do present themselves as the most likely contributors to these developments. The important and wide-ranging study conducted by Wheelahan et al. (2003) on behalf of the AQF almost certainly acted to raise the profile of RPL in the sector, even if not all universities formally responded to the consortium's request for information. The AVCC's consequential endorsement of the AQF Guidelines that arose from the consortium's recommendations would have only further raised the profile of RPL in the sector. Furthermore, the aforementioned efforts to improve linkages between the TAFE and higher education sectors, whilst focusing on credit transfer, have arguably highlighted the need for universities to do more to recognise informal learning directly and not just via the recognition-by-association that occurs when a university allows credit transfer for a VET qualification that itself often contains elements of RPL.

The rapid development of RPL policy in Australian universities is a strong indication that many of the historical barriers to RPL in the higher education sector are now being re-examined and even overturned. For example, there has previously been a perception that universities view RPL as an 'inferior' form of learning by comparison to learning acquired as part of a university degree (Taylor \& Clemans, 2000). However, the value statements now found in many universities' RPL policies are evidence that informal learning is not only accepted, but attains the same status, or rank, as learning achieved in a more traditional, formal environment. Associated with this hierarchical ranking of knowledge is a previously held conviction that tertiary education carries with a certain je ne sais quoi: that a formal educational environment imparts in students certain skills and attributes missing in students who receive significant amounts of RPL (Davison, 1996; Haeger, 1998; Wheelahan, 2003). Yet this study indicates that perhaps universities have resolved the potential conflict between recognising informal learning and providing that 'something else' through the expedient use of limitations to the maximum amount of credit awarded. Another belief is that RPL will have a detrimental effect on educational standards (Australian Education Union, 2004; Nelson, 2002). This concern is linked to the assumption that RPL procedures are inevitably associated with minimal and very specific, finite course outcomes as set out in a vocational, competency-based philosophy of education (Harrz-Hindmarsh, 1992). Yet the contemporary policies reveal that the issue of academic rigour is paramount and universal, with RPL processes constantly being placed in the context of the integrity of the qualification to which it is related. 
The extent to which avowed policy is ultimately enacted did not fall inside the boundaries of this research and deserves further attention. In his seminal work Education reform: A critical and post-structural approach Stephen Ball (1994) observed that policy is both 'text and action, words and deeds, it is what is enacted as well as what is intended' (p. 10). Understanding the ways in which academic and professional staff at the sharp end of teaching and learning understand, interpret and deliver formal university policy will provide clearer insight into the extent to which RPL is supported by the Australian higher education sector. Nonetheless, there is evidence that, at least in their stated position, universities are responding to pressures to deliver teaching and learning policies that more fully address the needs of prospective students seeking recognition of their prior non-formal learning experiences.

\section{Acknowledgements}

I would like to thank the Editors of Higher Education Research and Development and two anonymous referees for their constructive comments on an earlier version of this paper. However, any opinions expressed or errors contained in this article are those of the author alone.

\section{References}

Australian Catholic University. (2003). Recognition of prior learning (online policy) Retrieved February 13, 2006, from http://www.acu.edu.au/course_areas/ Undergraduate_Courses/How_to_Apply/index.cfm

Australian Education Union. (2004). AEU Response to Australia's teachers. Australia's future: Advancing innovation, science, technology and mathematics. Retrieved January 20, 2007, from http://www.aeufederal.org.au

Australian Vice-Chancellors' Committee (AVCC). (1993) Credit transfer principles. Guidelines on recognition of prior learning. Canberra: Australian Vice-Chancellors' Committee.

AVCC. (2000). Pathways to partnership: Qualification linkages between VET and higher education. Retrieved February 27, 2007, from http://www.avcc.edu.au

Ball, S. (1994) Education reform: A critical and post-structural approach. Buckingham, UK: Open University Press.

Berelson, B. (1952) Content analysis in communications research. New York: Free Press.

Cameron, R. (2004). Recognition of prior learning (RPL) in 2004: A snapshot. Retrieved 9 March, 2004, from http://www.ala.asn.au/research

Central Queensland University (1994). CQU Policy on 'Recognition of Prior Learning. Retrieved December 13, 2005, from http://www.cqu.edu.au

Charles Darwin University. (1999) Skills recognition: Higher education and VET (online policy). Retrieved 6 February, 2006, from http://eagle.cdu.edu.au/ntu/apps/ntuinfo.nsf/ WWWView/Policy_317

Childs, M., Ingham, V., \& Wagner, R. (2002). Recognition of prior learning on the web: A case of Australian universities. Australian Journal of Adult Learning, 42(1), 39-56.

Davison, T. (1996). 'Equivalence' and the recognition of prior learning (RPL). Australian Vocational Education Review, 3, 11-18.

Department of Education, Science and Training. (2002). Varieties of learning: The interface between higher education and vocational education and training. Retrieved March 6, 2006, from http://www.dest.gov.au

Doddrell, E. (2002). The evolution of RPL in Australia: From its origins to future possibilities. Unpublished thesis, Murdoch University, Western Australia.

Duffy, M. (2002). Methodological issues in web-based research. Journal of Nursing Scholarship, $34(1), 83-88$. 
Earl, J., Martin, A., McCarthy, J., \& Soule, S. (2004). The use of newspaper data in the study of collective action. Annual Review of Sociology, 30, 65-80.

Edith Cowan University. (n.d.) Advanced standing (online policy). Retrieved April 22, 2007, from http://www.ecu.edu.au/GPPS/policies_db/tmp/ac059.pdf

Fox, T. (2005). Adult learning and the recognition of prior learning: The 'white elephant' in Australian universities. Australian Journal of Adult Learning, 45(3), 352-370.

Gallacher, J., \& Feutrie, M. (2003). Recognising and accrediting informal and non-formal learning in higher education: An analysis of the issues emerging from France and Scotland. European Journal of Education, 38(1), 71-83.

Griffith University (2006) Credit transfer policy (online policy). Retrieved April 22, 2007, from http://www62.gu.edu.au/policylibrary.nsf/mainsearch/ fec69591c3cd44494a256b9e006a3273?opendocument\#End

Haeger, P. (1998). Recognition of informal learning: Challenges and issues. Journal of Vocational Education and Training, 50(4), 521-535.

Harrz-Hindmarsh, J. (1992, November). Recognition of prior learning: A summary of an exploratory study in a New Zealand university. Paper presented to the NZARE/AARE Conference, Wellington, New Zealand.

Holsti, O. (1969). Content analysis for the social sciences and humanities. Reading, MA: Addison-Wesley.

International Labour Office. (2004). Lifelong learning in Asia and the Pacific. Retrieved April 9,2005 , from http://www.ilo.org

Michelson, J. (1996). 'Auctoritee' and 'experience': Feminist epistemology and the assessment of experiential learning. Feminist Studies, 22(3), 627-656.

Ministerial Council on Education, Employment, Training and Youth Affairs. (2005). Principles for good practice information provision on credit transfer and articulation from vocational training and education to higher education. Retrieved June 1, 2007, from http:// www.mceetya.edu.au

Monash University. (2002). Recognition of prior learning policy (online policy). Retrieved June 6, 2006, from http://www.adm.monash.edu/unisec/academicpolicies/policy/ priorlearning.html

National Board of Employment, Education and Training. (1990). Seminar on credit transfer, course length and nomenclature and postgraduate studies: Summary of proceedings. Canberra: Australian Government Printing Service.

National Board of Employment, Education and Training. (1994). Credit transfer and the recognition of prior learning. Canberra: Australian Government Printing Service.

Nelson, B. (2002). Higher education at the crossroads: An overview paper. Canberra: Australian Government Printing Service.

Nelson, B. (2005, March) Underpinning prosperity: Our agenda in education, science and training. A speech by Dr. Brendan Nelson at the Sustaining Prosperity Conference at the University of Melbourne. Retrieved June 13, 2007 from http://www.dest.gov.au/ministers/ nelson/mar_05/speech_310305.htm

Pitman, T. (2006). Frequency of 'RPL' versus 'credit transfer' as a topic recurring in Hansard records of each Australian state or territory lower house over the period 2000-2005. Unpublished raw data.

Taylor, T., \& Clemans, A. (2000). Avoiding the hoops: A study of recognition of prior learning processes in Australian faculties of education. Asia-Pacific Journal of Teacher Education, 28(3), 263-281.

University of Canberra. (n.d.). Recognition of prior learning (online policy). Retrieved January 19, 2007, from http://www.canberra.edu.au/secretariat/rpl/rpl_index.html

University of Newcastle. (2000). Policy on recognition of prior learning (online policy) Retrieved February 2, 2006, from http://www.newcastle.edu.au/policy/academic/general/ recog_priorlearn.pdf

University of Queensland. (2005). Credit for previous studies and recognised prior learning (online policy). Retrieved January 19, 2006, from http://www.uq.edu.au/hupp/ index.html?page $=25103 \&$ pid $=25075$

University of South Australia. (1993). Recognition of prior learning for credit, exemption and studies-in-lieu (online policy). Retrieved January 19, 2006, from http://www.unisa.edu.au/ policies/policies/academic/A13.asp 
University of Sydney. (1998). Admission: Advanced standing, credit and exemption policy (online policy). Retrieved 14 July, 2006, from http://www.usyd.edu.au/ab/policies/ Adv_Standing_Credit_Exemption.pdf

University of Western Australia. (1995). Recognition of prior learning (online policy). Retrieved February 13, 2006, from http://www.secretariat.uwa.edu.au/home/policies/ admissions/rpluwa

Victoria University. (n.d.). Recognition - RPL/RCC, credit transfer and advanced standing (online policy). Retrieved February 2, 2006, from http://www.vu.edu.au/library/pdf/ 6ArtsAppendix.pdf

Watson, L. (2003). Lifelong learning in Australia. Retrieved July 12, 2005, from http:// www.canberra.edu.au/lifelong/

West, R. (1998). Learning for life: Final report of the Review of Higher Education Financing and Policy. Canberra: JS McMillan.

Wheelahan, L., Dennis, N., Firth, J., Miller, P., Newton, D., Pascoe, S., et al. (2003). Recognition of prior learning: Policy and practice in Australia. Report commissioned by the Australian Qualifications Framework Advisory Board. Retrieved February 5, 2004, from http:// www.scu.edu.au/research/rpl/

Wright, K. (2005). Researching internet-based populations: Advantages and disadvantages of online survey research, online questionnaire authoring software packages and web survey services. Journal of Computer-Mediated Communication, 10(3) (online version) retrieved 15 April, 2008, from http://www.blackwell-synergy.com 